\title{
Empathy With Patients and Post-Traumatic Stress Response in Verbally Abused Healthcare Workers
}

\author{
Soo-hyun Nam¹, Dong-Wook Lee ${ }^{2}$, Hwa-yeon $\mathrm{Seo}^{3}$, Yun-Chul Hong ${ }^{2}$, \\ Je-Yeon Yun ${ }^{4}$, Sung-jun $\mathrm{Cho}^{5}$, and Nami Lee ${ }^{1,4 凶}$ \\ ${ }^{1}$ Human Rights Center, Seoul National University Hospital, Seoul, Republic of Korea \\ 2Department of Preventive Medicine, College of Medicine, Seoul National University, Seoul, Republic of Korea \\ ${ }^{3}$ Public Health Medical Service, Seoul National University Hospital, Seoul, Republic of Korea \\ ${ }^{4}$ Department of Psychiatry, Seoul National University Hospital, Seoul, Republic of Korea \\ ${ }^{5}$ Department of Psychiatry, Kangbuk Samsung Hospital, Seoul, Republic of Korea
}

\begin{abstract}
Objective The current study examined the differential empathic capacity, post-traumatic symptoms, and coping strategies in healthcare workers (HCWs) according to the exposure of verbal or physical workplace violence (WPV).

Methods Using online survey, a total of $422 \mathrm{HCWs}$ employed at a training general hospital of South Korea participated and completed self-reporting questionnaires including the WPV questionnaire with coping strategy, the Jefferson Scale of Physician Empathy.

Results Those who experienced either only verbal violence or both physical and verbal violence had lower Jefferson Scale of Physician Empathy scores $(\mathrm{p}<0.05)$. Posttraumatic stress symptom severity was higher among people who experienced verbal violence than physical violence. HCWs' exposure to verbal violence was associated with severe posttraumatic symptoms and a low level of empathy with patients $(\mathrm{p}<0.05)$. More than half of the victims of verbal violence responded that they did not take any action, receive organizational protection, or peer support, while most physically-abused HCWs received institutional intervention or help from others.

Conclusion Our findings highlight the critical importance of reducing verbal violence, which may represent a larger psychological burden compared to physical violence, by actively implementing effective strategies and policies at the institutional level.
\end{abstract}

Psychiatry Investig 2021;18(8):770-778

Keywords Workplace violence; Healthcare workers; Empathy; Posttraumatic stress disorder; Mental health.

\section{INTRODUCTION}

Workplace violence (WPV) is defined as "incidents where staffs are abused, threatened, or assaulted in circumstances related to their work, including commuting to and from work, involving an explicit or implicit challenge to their safety, wellbeing or health." Healthcare workers (HCWs) tend to underreport WPV, given the tradition of enduring violence at work as part of their job. ${ }^{2}$ In previous studies, HCWs showed a higher risk of being injured via WPV, ${ }^{3-5}$ up to 16 times higher than

Received: February 20, 2021 Revised: May 5, 2021

Accepted: June 7, 2021

$\triangle$ Correspondence: Nami Lee, PhD

Department of Psychiatry, Seoul National University Hospital, 103 Daehakro, Jongno-gu, Seoul 03080, Republic of Korea

Tel: +82-2-2072-3761, Fax: +82-2-744-7241, E-mail: nami6107@naver.com

(a) This is an Open Access article distributed under the terms of the Creative Commons Attribution Non-Commercial License (https://creativecommons.org/licenses/by$\mathrm{nc} / 4.0$ ) which permits unrestricted non-commercial use, distribution, and reproduction in any medium, provided the original work is properly cited. other service industry workers for both mental and physical aspects. ${ }^{6}$ In South Korea, WPV toward HCW s has been increasing for decades. ${ }^{7}$ Incidents such as stabbing a physician to death in a general hospital's outpatient consulting room, biting a nurse's finger to the point of amputation during an L-tube procedure, and a diagnosed COVID-19 patient spitting to a medical staff attracted nationwide public attention. ${ }^{8-10}$

In addition to depression, anxiety, and burnout, post-traumatic stress disorder (PTSD) is one of the most frequent negative psychological consequences of WPV victims. ${ }^{11}$ Rosenthal et al. ${ }^{12}$ reported that $34.4 \%$ of HCWs experienced verbal or physical violence and among them, over $60 \%$ affirmed at least one posttraumatic symptom. A cross-sectional study conducted in UK reported one in 6 physicians screened positive for PTSD, and 2 in 5 for current anxiety and depression. ${ }^{5} \mathrm{HCWs}$ experience at least one symptom of PTSD, including the feeling of being intruded, having avoidant behavior, and experiencing hyper-arousal status. ${ }^{11,13}$ The WPV victims could suf- 
fer from the symptoms of burnout, lowered level of motivation, increased intention to leave, and poorer performance at workplace. ${ }^{14-16}$ Further, in cases of HCWs, they could also show the reduced empathic attitude for patients due to the lack of energy/affection. One systematic review conducted in UK found a negative association between burnout and empathy in HCWs. ${ }^{17}$ As emotional exhaustion, defined as lack of energy and affection, is core dimensions of burnout, empirical evidence supports that HCWs could suffer from the reduced empathic attitude for patients due to the lack of energy and affection. As empathy has been regarded as an elementary affection for therapeutic alliance, ${ }^{18,19}$ lowered level of empathy in HCWs after experiencing WPV could induce medical mistakes, diagnostic inaccuracy, patients' undue reports of symptoms, and poorer clinical outcomes. ${ }^{20-22}$

Despite these well-known detrimental effects of WPV on mental health, the differential impact of WPV subtypes (physical or verbal) on the empathic capacity of HCW has received little attention. ${ }^{23}$ Previous research revealed that association of physical violence with depression and anxiety was not statistically significant, however, verbal violence was strongly associated with anxiety and depression, low self-esteem and avoidance and intrusion in a sample of battered women in Italy. ${ }^{24}$ On the contrary, Zafar et al. ${ }^{5}$ have also reported that HCWs who experienced physical violence were about 7 times more likely to be screened positive for PTSD than those who experienced verbal violence. Therefore, no consistent conclusion can be drawn from the existing literature in regards to the relationship between the type of WPV and its detrimental psychological impact. Providing prevention programs regarding WPV against HCWs, according to the differential types of violence, would allow HCWs to be equipped with more practical tools of how to deal with violence and its aftermath. Thus, we conducted a survey to investigate the possible differences in psychological outcomes between the verbal and physical violence at workplace by comparing the differences of 1) the empathic capacity, 2) post-traumatic symptoms, and 3) coping skills in HCW, segregated according to the degrees of exposure to the verbal and/or physical violence at workplace.

\section{METHODS}

\section{Study population and recruitment}

A total of 609 HCWs (including doctors, registered nurses, pharmacists, medical technicians, and non-health professionals at a training hospital) participated in the current study between March 20 and June 1, 2019. All participants were recruited through online posting and e-mails; data collection was conducted using the anonymous self-reporting questionnaires delivered via web-based link. Self-reporting questionnaires were: the WPV experiences, perceived empathic capacity for patients, posttraumatic symptoms, and demographic information (age, gender, educational level, marital status, working department, years working at the current institution, and work shift). After excluding the data with omitted response(s), finally a total of 422 responses were used for the statistical analyses. Participants were asked to provide written consent prior to the beginning of the survey and voluntarily responded to selfadministered questionnaires. The study was approved by the Institutional Review Board of Seoul National University Hospital (IRB No: 1902-038-1009).

\section{Study protocol}

\section{WPV questionnaire}

The exposures of WPV were measured using a self-reporting questionnaire. ${ }^{25}$ The questionnaire consisted of four sections: 1) demographic (age, gender, educational level, marital status) and workplace-related features (department, number of coworkers, employment status, years working at the current institution, and shift work); 2) perceived verbal or physical violence within the last 12 months (frequency of violent incidents, places where the violence took place, characteristics of the perpetrators, how individuals responded to the violence, actions taken to investigate the causes of violence, the consequences of the perpetrators' offenses, and whether employers or supervisors provided support such as counseling or reporting the incident); 3) four clinical symptoms of PTSD (with responses of 1 [not at all] to 5 [extremely]) including the "repeated, disturbing memories, thoughts, or images of the attack," "avoiding thinking about or talking about the attack or avoiding having feelings related to it," "being super-alert or watchful and on guard," and "feeling like that everything you did was an effort" comprising the Diagnostic and Statistical Manual of Mental Disorders (DSM)-IV-based diagnostic criteria of PTSD ${ }^{26}$ Summed scores indicates the degree of PTSD and scores above 14 represent the presence of PTSD; ;7,28 4) coping strategy including "took no action or individual action," "received help from family, colleagues, or organization"

\section{Empathy scale}

Jefferson Scale of Physician Empathy (JSPE) was composed of 20 -items. ${ }^{29}$ Using a seven-point Likert scale ranging from "strongly disagree" to "strongly agree", it measures three subdimensions of empathy including the 1) perspective-taking (Items $2,4,5,9,10,13,15,16,17,20), 2$ ) compassionate care (Items 1, 7, 8, 11, 12, 14, 18, 19), and 3) walking in the patient's shoes, that is, understanding the patient's experiences (Items 3, 6). 


\section{Statistical analyses}

Participant characteristics were described and frequencies of experienced violence (physical and verbal in the last year) were calculated. We performed the Shapiro-Wilk test to assess the normality of JSPE and PTSD scores. According to the violation of the normality assumption, either the Student's t-test and analysis of variance or the Mann-Whitney test and Kruskal-Wallis test were performed to compare the differences in JSPE scores and the scores on the entire PTSD questionnaire sorted by experience, frequency, and assailant of WPV.

We classified participants into four groups according to the type of WPV they experienced (physical violence [yes or no] and verbal violence [yes or no]). We tested the differences in JSPE scores between the groups that experienced WPV and the groups that did not, while adjusting for age, gender, marital status, educational level, and job classification by using multivariate linear regression models. Finally, among those who experienced physical or verbal violence, posttraumatic symptoms were measured according to their coping strategies for WPV. The means and standard deviations (SDs) for four questions rated on a five-point Likert scale and a sum of questions were calculated for the coping strategies (no action or individual action vs. received help from family, colleagues, or organization). The differences in scores on the PTSD questionnaire were tested by using multivariate linear regression models, adjusting for age, gender, marital status, educational level, and job classification.

\section{RESULTS}

\section{Demographic and work-related characteristics}

Table 1 depicts the characteristics of the study participants. A total of $422 \mathrm{HCWs}$ participated in our study, including 324 (76.8\%) females and 98 (23.2\%) males. The majority of participants were 195 people of $30-39$ years of age (46.2\%), followed by 114 of those under 30 years of age (27.0\%), and 78 people of $40-49$ years of age (18.5\%). Most participants were educated at the college level or above (410 people, $97.2 \%$ ). Common job positions among our participants were nurses (227 people, $53.8 \%$ ), doctors ( 80 people, $19.0 \%$ ), and medical technicians (52 people, $12.3 \%$ ). The number of those who experienced WPV were 55 people (13.0\%) for physical violence and 196 people (46.5\%) for verbal violence. Considering both types of violence, there were 11 participants (2.6\%) who experienced only physical violence, and 152 participants (36.0\%) who experienced only verbal violence, and 44 participants (10.4\%) who experienced both physical and verbal violence in the workplace.

\section{Profiles of WPV, empathic capacity, and post-traumatic symptoms in HCW}

Among those who experienced physical violence, 38 people (69.1\%) experienced it less than once a month and 17 people (30.9\%) experienced it once a month or more frequently. Physical violence was frequently perpetrated by a patient or their family $(\mathrm{n}=43,78.2 \%)$, followed by a coworker or superior $(\mathrm{n}=$ $10,18.2 \%)$, or a visitor $(n=2,3.6 \%)$. Those who experienced verbal violence once a month or more frequently numbered were 101 people (51.5\%). Perpetrators of verbal violence were mostly patients or their family ( $\mathrm{n}=112,57 \%)$, followed by coworkers or superiors ( $\mathrm{n}=57,29.1 \%)$, or visitors of patient $(\mathrm{n}=$ $27,13.8 \%)$.

JSPE and PTSD scores according to experiences and characteristics of WPV (physical and verbal) are presented in Table 2. Fifty-five workers (13.0\%) and 196 workers (46.5\%) have experienced physical violence and verbal violence in the last year, respectively. The participants who experienced physical violence reported significantly lower JSPE than those who did $\operatorname{not}(87.8$ [SD \pm 20.8$]$ vs. 92.9 [SD \pm 16.8$]$, respectively; $\mathrm{p}=0.040$ ). JSPE score was also significantly lower among workers experienced verbal violence than workers who did not (89.9 [SD \pm $18.1]$ vs. 94.3 [SD \pm 16.5$]$, respectively; $\mathrm{p}=0.009$ ). There was no difference in JSPE and in PTSD score, by the frequency of violence or the type of assailant among those who experienced physical violence. Frequencies of exposure to verbal violence $(<1 /$ month vs. $\geq 1 /$ month) were significantly associated with PTSD score (13.4 [SD \pm 3.8 ] vs. 15.5 [SD \pm 3.1 ], respectively; $\mathrm{p}=$ $0.035)$ in the group of those who experienced verbal violence.

Figure 1 presents the differences in JSPE scores according to groups divided by their experiences of physical and verbal violence. Compared to workers who did not experience WPV within the last year, after adjusting demographic variables, workers with experience of verbal violence only and workers with experience of both physical and verbal violence had significantly lower score of JSPE than workers without experience of workplace violence, as 4.4 (95\% confidence interval [CI]: - 7.9, $0.9 ; \mathrm{p}=0.014)$ and 7.2 (95\% CI: $-13.9,-0.5 ; \mathrm{p}=0.035)$, respectively.

\section{Coping strategy and post-traumatic symptom in HCW}

Total scores for PTSD symptoms according to the type of WPV and coping strategies are depicted in Table 3. Among victims of WPV, PTSD scores over 14 points were more common in verbal violence (61.2\%) than physical violence (54.6\%). Table 3 also presents the differences in coping strategies according to the type of WPV. More than half of the victims of verbal violence responded that they did not take any action or receive organizational protection or peer support, while most physically-abused HCWs received institutional intervention 
Table 1. Participants' characteristics and experience of workplace violence

\begin{tabular}{|c|c|c|c|c|c|c|c|c|c|c|}
\hline & \multirow{3}{*}{$\begin{array}{c}\text { Total } \\
\mathrm{N}(\%)\end{array}$} & \multicolumn{3}{|c|}{$\begin{array}{l}\text { Experienced workplace } \\
\text { violence* in the last year }\end{array}$} & \multicolumn{3}{|c|}{$\begin{array}{l}\text { Experienced physical } \\
\text { violence in the last year }\end{array}$} & \multicolumn{3}{|c|}{$\begin{array}{c}\text { Experienced verbal } \\
\text { violence in the last year }\end{array}$} \\
\hline & & Yes & No & & Yes & No & \multirow{2}{*}{$\mathrm{p}$} & Yes & No & \multirow{2}{*}{$\mathrm{p}$} \\
\hline & & N (\%) & N (\%) & & $\mathrm{N}(\%)$ & N (\%) & & N (\%) & N (\%) & \\
\hline Total & $422(100)$ & $215(51.0)$ & $207(49.0)$ & & $55(13.0)$ & $376(87.0)$ & & $196(46.5)$ & $226(53.5)$ & \\
\hline Gender & & & & $<0.001$ & & & 0.102 & & & $<0.001$ \\
\hline Male & $98(23.2)$ & $65(66.3)$ & $33(33.7)$ & & $8(8.2)$ & $90(91.8)$ & & $31(31.6)$ & $67(68.4)$ & \\
\hline Female & $324(76.8)$ & $150(46.3)$ & $174(53.7)$ & & $47(14.5)$ & $277(85.5)$ & & $165(50.9)$ & $159(49.1)$ & \\
\hline Age (y) & & & & 0.014 & & & 0.040 & & & 0.045 \\
\hline$<30$ & $114(27.0)$ & $54(47.4)$ & $60(52.6)$ & & $22(19.3)$ & $92(80.7)$ & & $56(49.1)$ & $58(50.9)$ & \\
\hline $30-39$ & $195(46.2)$ & $91(46.7)$ & $104(53.3)$ & & $25(12.8)$ & $170(87.2)$ & & $98(50.3)$ & $97(49.7)$ & \\
\hline $40-49$ & $78(18.5)$ & $44(56.4)$ & $34(43.6)$ & & $7(9.0)$ & $71(91.0)$ & & $33(42.3)$ & $45(57.7)$ & \\
\hline$>50$ & $35(8.3)$ & $26(74.3)$ & $9(25.7)$ & & $1(2.9)$ & $34(97.1)$ & & $9(25.7)$ & $26(74.3)$ & \\
\hline Marital status & & & & $<0.001$ & & & 0.002 & & & 0.002 \\
\hline Single & $206(48.8)$ & $87(42.2)$ & $119(57.8)$ & & $38(18.5)$ & $168(81.5)$ & & $110(53.4)$ & $96(46.6)$ & \\
\hline Marriage & $213(50.5)$ & $128(60.1)$ & 85 (39.9) & & $16(7.5)$ & $197(92.5)$ & & $83(39.0)$ & $130(61.0)$ & \\
\hline Divorced & $3(0.7)$ & $0(0)$ & $3(100)$ & & $1(33.3)$ & $2(66.7)$ & & $3(100.0)$ & $0(0)$ & \\
\hline Education & & & & 0.071 & & & 0.059 & & & 0.026 \\
\hline High school & $12(2.8)$ & $10(83.3)$ & $2(16.7)$ & & $1(8.3)$ & $11(91.7)$ & & $1(8.3)$ & $11(91.7)$ & \\
\hline College & $261(61.9)$ & $129(49.4)$ & $132(50.6)$ & & $42(16.1)$ & $219(83.9)$ & & $123(47.1)$ & $138(52.9)$ & \\
\hline Graduate school & $149(35.3)$ & $76(51.0)$ & $73(49.0)$ & & $12(8.1)$ & 137 (91.9) & & $72(48.3)$ & $77(51.7)$ & \\
\hline Job & & & & $<0.001$ & & & 0.008 & & & $<0.001$ \\
\hline Doctors & $80(19.0)$ & $52(65.0)$ & $28(35.0)$ & & $5(6.3)$ & $75(93.8)$ & & $27(33.8)$ & $53(66.3)$ & \\
\hline Medical technicians & $52(12.3)$ & $35(67.3)$ & $17(32.7)$ & & $2(3.9)$ & $50(96.2)$ & & $17(32.7)$ & $35(67.3)$ & \\
\hline Pharmacist & $13(3.1)$ & $5(38.5)$ & $8(61.5)$ & & $1(7.7)$ & $12(92.3)$ & & $7(53.9)$ & $6(46.2)$ & \\
\hline Nurse & $227(53.8)$ & $87(38.3)$ & $140(61.7)$ & & $43(18.9)$ & $184(81.1)$ & & $132(58.2)$ & $95(41.9)$ & \\
\hline Assistant nurse & $10(2.4)$ & $7(70.0)$ & $3(30.0)$ & & $1(10.0)$ & $9(90.0)$ & & $2(20.0)$ & $8(80.0)$ & \\
\hline Non-health professionals & $40(9.4)$ & $29(72.5)$ & $11(27.5)$ & & $3(7.5)$ & $37(92.5)$ & & $11(27.5)$ & $29(72.5)$ & \\
\hline Duration (y) & & & & 0.301 & & & 0.118 & & & 0.556 \\
\hline$<3$ & $95(22.5)$ & $52(54.7)$ & $43(45.3)$ & & $11(11.6)$ & $84(88.4)$ & & $41(43.2)$ & $54(56.8)$ & \\
\hline $3-5$ & $69(16.4)$ & $33(47.8)$ & $36(52.2)$ & & $15(21.7)$ & $54(78.3)$ & & $34(49.3)$ & $35(50.7)$ & \\
\hline $6-10$ & $113(26.8)$ & $49(43.4)$ & $64(56.6)$ & & $16(14.2)$ & $97(85.8)$ & & $59(52.2)$ & $54(47.8)$ & \\
\hline $11-15$ & $65(15.4)$ & 37 (56.9) & $28(43.1)$ & & $7(10.8)$ & $58(89.2)$ & & $27(41.5)$ & $38(58.5)$ & \\
\hline$>15$ & $80(19.0)$ & $44(55.0)$ & $36(45.0)$ & & $6(7.5)$ & $74(92.5)$ & & 35 (43.8) & $45(56.3)$ & \\
\hline
\end{tabular}

Chi-squared test was performed to test the differences. * ${ }^{*}$ verbal violence and/or physical violence

or help from others. There was no statistically significant difference in PTSD score after experiences of workplace violence.

\section{DISCUSSION}

In our study, victimized HCWs showed a low level of empathy with patients. This finding is similar to previous researches indicating that WPV hinders understanding patients and causes inappropriate care with weakened empathy toward patients. ${ }^{30,31}$ Having a high level of empathy is associated with HCWs' psy- chological well-being. ${ }^{32}$ Establishing immediate WPV interventions are required in order to maintain empathy and work efficiency.

Our study confirms that the impact on HCW's empathy depends on the types of violence: physical and verbal. Experiences of verbal violence heightened the risk of lowered empathy, whereas physical violence did not show significant effects. This result aligns with previous study in which verbal violence had a significant effect on depression, anxiety, and physical symptoms in comparison with injuries inflicted by physical violence. ${ }^{33}$ 
Table 2. Experiences of workplace violence, empathy with patients, and posttraumatic symptoms

\begin{tabular}{|c|c|c|c|c|c|c|}
\hline & \multicolumn{3}{|c|}{ Physical violence } & \multicolumn{3}{|c|}{ Verbal violence } \\
\hline & \multicolumn{2}{|c|}{ JSPE } & \multirow{2}{*}{$\begin{array}{c}\text { PTSD score } \\
\mathrm{N}(\%)\end{array}$} & \multicolumn{2}{|c|}{ JSPE } & \multirow{2}{*}{$\begin{array}{c}\text { PTSD score } \\
\mathrm{N}(\%)\end{array}$} \\
\hline & $\mathrm{N}(\%)$ & Mean \pm SD & & $\mathrm{N}(\%)$ & Mean \pm SD & \\
\hline \multicolumn{7}{|l|}{ Experience of violence } \\
\hline No & $367(87.0)$ & $92.9 \pm 16.8^{*}$ & - & $226(53.6)$ & $94.3 \pm 16.5^{*}$ & - \\
\hline Yes & $55(13.0)$ & $87.8 \pm 20.8$ & - & $196(46.4)$ & $89.9 \pm 18.1$ & - \\
\hline \multicolumn{7}{|l|}{ Frequency ${ }^{\dagger}$} \\
\hline$<1 /$ month & $38(69.1)$ & $89.5 \pm 21.4$ & $12.8(3.4)$ & $95(48.5)$ & $91.0 \pm 16.6$ & $13.4(3.8)^{*}$ \\
\hline$\geq 1 /$ month & $17(30.9)$ & $84 \pm 19.5$ & $14.1(3.0)$ & $101(51.5)$ & $84.1 \pm 19.0$ & $15.5(3.1)$ \\
\hline \multicolumn{7}{|l|}{ Assailants $^{\dagger}$} \\
\hline Patients (or their families) & $43(78.2)$ & $88.9 \pm 20.2$ & $12.9(3.2)$ & $112(57.1)$ & $90.9 \pm 17.8$ & $13.3(3.6)$ \\
\hline Coworkers (or superiors) & $10(18.2)$ & $80.7 \pm 23.5$ & $14.3(4.0)$ & $57(29.1)$ & $89.5 \pm 19.4$ & $14.7(3.5)$ \\
\hline Others (visitors, external workers, general public) & $2(3.6)$ & $99.5 \pm 21.9$ & $13.0(2.8)$ & $27(13.8)$ & $86.5 \pm 16.8$ & $15.3(2.9)$ \\
\hline
\end{tabular}

Differences in JSPE scores according to experiences of physical or verbal violence were tested using the Student's t-test or ANOVA. The Mann-Whitney test and Kruskal-Wallis test were performed to assess the differences in JSPE and PTSD scores according to the frequency of violence and the perpetrator of the violent events. ${ }^{*} \mathrm{p}<0.05$; ${ }^{\dagger}$ among participants who experienced physical or verbal violence in the last year. JSPE, Jefferson Scale of Physician Empathy; PTSD, Posttraumatic Stress Disorder

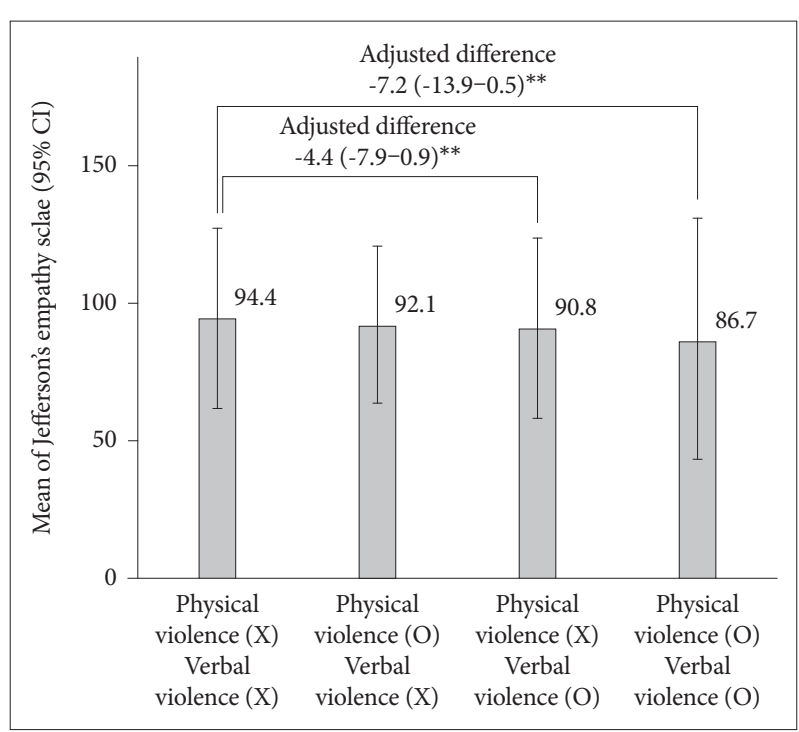

Figure 1. Types of experience of workplace violence and healthcare workers's empathy. ${ }^{* *}$ differences between the groups with and without experience, adjusted for age, gender, marital status, education, and job classification.

It is also consistent with other studies suggesting that, different from common sense, verbal violence has a greater impact on mental health and musculoskeletal pain than does physical violence. ${ }^{34}$ However, in health care facilities, experience of physical violence is usually one-off thing, while verbal violence can occur in a more persistent and pervasive manner, and victims can be more susceptible to negative health outcomes. ${ }^{35-37}$ Verbal violence can be experienced as more personally demeaning and humiliating. Recent network analyses reported that verbal violence which makes individuals feel worthless and damage one's self-esteem serve as connector in the verbal abuse-depres- sion and anxiety-social interaction features. ${ }^{38}$ Statistical back up related to personal implication with verbal assaults demonstrated that verbal aggression which appears targeted, demeaning or humiliating has been significantly associated with higher experienced anger provocation ${ }^{39}$ and depression..$^{40}$ For this reason, victims may blame themselves for the incident and question their qualifications as medical professionals. ${ }^{41}$ Verbal abuse may hurt victims' self-esteem longer and deeper. Legal interventions are not easily or promptly given for verbal abuse, while overt physical violence is usually punished and compensation for the adversity can be ordered by court. Organizational protection and support from colleagues sometimes underestimate the significance of verbal violence. Many victims of verbal violence may be hurt by the biased judgment of others. ${ }^{42}$ Lack of adequate support systems or collegial sympathy and appreciation may discourage the verbally abused and possibly reduce their capacity to be empathetic with patients. ${ }^{43}$ Patients who have cognitive deficits, dementia, and other serious psychiatric problems may become verbal abuse perpetrators. ${ }^{44}$ They may devalue the quality of the services and project their anger and frustration toward HCWs. Verbal abuse among hospital members or long-term care patients can occur for longer periods of time than episodic physical abuse, which can be more detrimental to mental health, since victims would feel helpless with self-blaming attitudes. While bodily traumas can be noticed and healed with immediate and direct remedies, psychological traumas are often ignored and neglected without clear timeline or boundary between prevailing authoritarian manners and abusive conducts.

In our study, the number of participants with PTSD scores of 14 points or above was higher for those who experienced 
Table 3. Posttraumatic symptoms according to the coping strategies used to handle workplace violence

\begin{tabular}{|c|c|c|c|c|c|}
\hline & \multicolumn{3}{|c|}{ PTSD Score $\geq 14$} & \multicolumn{2}{|c|}{ PTSD Score } \\
\hline & $\mathrm{N}(\%)$ & $\mathrm{N}(\%)$ & $\mathrm{p}$ value & Mean \pm SD & $\mathrm{p}$ value \\
\hline Physical violence & $55(100.0)$ & $30(54.6)$ & 0.637 & & 0.487 \\
\hline No action or individual action & $18(32.7)$ & $9(50.0)$ & & $13.2 \pm 3.5$ & \\
\hline Received help from family, colleagues, or organization & $37(67.3)$ & $21(56.8)$ & & $13.2 \pm 3.3$ & \\
\hline Verbal violence & $196(100.0)$ & $120(61.2)$ & 0.231 & & 0.433 \\
\hline No action or individual action & $116(59.2)$ & $67(57.8)$ & & $13.8 \pm 3.9$ & \\
\hline Received help from family, colleagues, or organization & $80(40.8)$ & $53(66.3)$ & & $14.3 \pm 3.1$ & \\
\hline
\end{tabular}

Chi-squared test and multivariate linear regression test were performed to test the differences. Differences in PTSD score were tested with the adjustment for age, gender, marital status, education, and job classification. PTSD, Posttraumatic Stress Disorder; SD, standard deviation

verbal (without physical) abuse than for those who experienced physical (without verbal) abuse. This result is consistent with previous study in which the percentage of participants with PTSD scores of 14 points or higher was $28 \%$ for cases of verbal violence and $19.6 \%$ for cases of physical violence. ${ }^{45}$

Owing to the urgent nature of medical care, medical workers who endure verbal violence cannot be easily repositioned. HCWs are usually trained be tolerant of verbal abuse resulted from patients' disease. If the perpetrator is a patient, rejection or eviction of perpetrators is often legally or ethically difficult, owing to medical staff's beliefs and common sense that "refusal of care is not ethically right." These factors play a role in aggravating "re-experience" symptoms of PTSD. ${ }^{46}$

Physical restraint has no effect on verbal violence; ${ }^{47}$ although control over violence is critical for the safety of the abuser and the abused, since loss of psychological autonomy or agency in a traumatic event causes further distress. ${ }^{46}$ Thus, the self-efficacy and empowerment to solve a threatening situation is important for HCWs who suffered from verbal violence. ${ }^{48}$ Encouraging self-confidence against violence may prevent serious burnout symptoms. ${ }^{49}$

Most verbally abused victims in this study reported that they did not take any action or report incidents. Similar trends were found in previous studies conducted in other Asian countries. ${ }^{50,51}$ Meanwhile, in Germany, $60.3 \%$ of victims reported the incidents through formal procedures, while $97 \%$ directly reported the incidents to their supervisors. ${ }^{52}$ These results can be partly attributed to cultural differences between Asian and Western countries. In South Korea, there is a particularly strong cultural tendency to suppress the expression of HCW's personal dissatisfaction or negative affections and to take HCW's sacrifice for granted. ${ }^{44}$ Enduring unfair treatment or unreasonable situations is often attributed as part of the job. Further, previous study presented that the lack of appropriate measures, legal systems, and effective employee training on WPV and WPV prevention could be a fundamental reason why most victims responded that they took no action or pretended as if it never happened. ${ }^{53}$ Given this context, workplace harassment preven- tion law in Korea came into effect in July of 2019. Considering government controlled nationwide insurance system with low payment and high quality service, the workload of HCWs in South Korea is far heavier than in other developed countries. ${ }^{53}$ Busy hospital settings with short allotment of consultation and fewer medical professionals may lead patients and their families to be more resentful towards HCWs. Therefore, it is necessary to observe the effects of legal and institutional measures against verbal violence in the future.

In summary, verbal violence impedes HCWs' ability to be empathetic and leads to a higher risk of PTSD symptoms compared to physical violence. For regulating verbal as well as physical WPV, legal and systemic assistance and well-designed medical literacy plans for the public should be further developed. If medical institutions focus mainly on physical violence, overlooking the negative impact of verbal violence, HCW's work efficiency will be impeded. The lack of appropriate legal actions and less developed training program related to WPV may be another fundamental reason why most victims take no action or pretend the violence never happened. ${ }^{54}$ Refusal to treat patients should strictly follow a lawful protocol by considering the degree of violence, legal appropriateness, and HCWs' competence. ${ }^{55} \mathrm{~A}$ physician may need to have the right to refer unruly and uncooperative patients to other doctors or safer hospitals after giving notice of the specific reasons for treatmenttermination and providing information regarding substitute treatment facilities. ${ }^{55}$ HCWs without legal and practical protection may struggle with demoralizing and dangerous situations, which is simultaneously harmful to the patients' support systems and countermeasures; policies such as zero-tolerance policies against verbal abuse are strongly demanded. An automatic phone explaining zero-tolerance policies and recording system is needed for the legal evidences and education for the public.

Preventive measures such as public campaigns and teaching of de-escalation at the institutional level also need to be implemented. Considering the heavy workload and irregular work schedules of HCWs, practical intervention including brief in- 
tervention or online-based platform for the prevention of WPV is needed. In recent previous study, WPV prevention program using online modules for 2 hours has been demonstrated ${ }^{56}$ and a brief intervention with one-session, 3-hour simulation training on WPV revealed improvement of staff's confidence against WPV. ${ }^{57}$ These results suggest that interventions at the institutional level are effective, and practical interventions and prevention programs must be developed and implemented according to the type of violence experienced.

Our study has several limitations. First, the cross-sectional design limits causal inferences concerning WPV and empathy. Second, we used self-reporting questionnaire to measure the exposure of WPV, despite the controversies on the objective evidences in defining WPV. Personal threshold of WPV may be also unalike according to susceptibility of each person and situational differences. However, subjective report is important, especially for managing psychological sequelae, despite lack of objective measuring devices on individual traumatic events. In addition, HCWs are well known to report WPV less than they actually went through since they are afraid of being criticized not to adept to defend themselves and evaluated to be less qualified by their supervisors and hospital managers. WPV is often misinterpreted as a clinical failure for being less empathetic. In our study, self-report procedure using smartphone answering method protecting confidentiality might enhance to report WPV more than person-to-person interview or formal recording using paper. Third, all the respondents in this survey were working in a general training hospital in a metropolitan area where the workload is more diverse and serious than other smaller local hospitals or clinics at rural area. Therefore, the findings of this study regarding WPV cannot be generalized to most healthcare workers. Finally, although physical violence and verbal violence groups are interdependent, we compared two groups using between-group differences tests in order to emphasize the traumatic effect of solitary verbal abuse for several reasons: Public health strategy against violence has focused preventing physical violence rather than verbal violence. Guards and material equipment protecting health care workers from physical violence have been prepared, while overlooking the effect of prevailing verbal abuse in hospitals.

Nevertheless, this study raises important issues as the findings have implications for the health of both patients and medical practitioners. Effective intervention techniques and policies can be developed taking into consideration our findings that healthcare workers who are subjected to verbal violence feel low empathy toward patients and experience stress while providing healthcare services.

\section{Availability of Data and Material}

The datasets generated or analyzed during the study are available from the corresponding author on reasonable request.

\section{Conflicts of Interest}

The authors have no potential conflicts of interest to disclose.

\section{Author Contributions}

Conceptualization: Nami Lee, Yun-Chul Hong, Soo-hyun Nam. Data curation: Nami Lee, Soo-hyun Nam. Formal analysis: Soo-hyun Nam, Dong-Wook Lee. Methodology: Dong-Wook Lee, Sung-jun Cho. Visualization: Dong-Wook Lee, Hwa-yeon Seo. Writing-original draft: Soo-hyun Nam, Nami Lee. Writing_review \& editing: Yun-Chul Hong, Je-Yeon Yun.

\section{ORCID iDs}

Soo-hyun Nam https://orcid.org/0000-0002-1342-2769

Dong-Wook Lee https://orcid.org/0000-0002-4023-3269

Hwo-yeon Seo https://orcid.org/0000-0002-0523-5816

Yun-Chul Hong https://orcid.org/0000-0001-9010-7271

Je-Yeon Yun https://orcid.org/0000-0002-5531-2410

Sung-jun Cho https://orcid.org/0000-0001-6981-0931

Nami Lee

\section{Funding Statement}

This study was supported by donated grants to Seoul national university hospital under the name of "the Rhie blended family Foundation" with support from Dr. Rhie SooBum. Dr. Rhie JungYeon and secretary general Rhie JuneKyue (Grant No: 900-00086).

\section{REFERENCES}

1. International Labour Organization, International Council of Nurses, World Health Organization, Public Services. International Joint Programme on Workplace Violence in Health Sector. Framework guidelines for addressing workplace violence in health sector. Available at: https://apps.who.int/iris/handle/10665/42617. Accessed September 23, 2018.

2. Berlanda S, Pedrazza M, Fraizzol M, de Cordova F. Addressing risks of violence against healthcare staff in emergency departments: the effects of job satisfaction and attachment style. BioMed Res Int 2019;2019: 5430870 .

3. Hamdan M, Hamra AA. Burnout among workers in emergency departments in Palestinian hospitals: prevalence and associated factors. BMC Health Serv Res 2017;17:407.

4. 4. Nowrouzi-Kia B, Chai E, Usuba K, Nowrouzi-Kia B, Casole, J. Prevalence of type II and type III workplace violence against physicians: a systematic review and meta-analysis. J Occup Environ Med 2019;10: 99-110.

5. Zafar W, Khan U, Siddiqui S, Jamali S, Razzak, J. Workplace violence and self-reported psychological health: Coping with post-traumatic stress, mental distress, and burnout among physicians working in the emergency departments compared to other specialties in Pakistan. J Emerg Med 2016;50:167-177.

6. Occupational Safety and Health Administration. Preventing workplace violence in healthcare. Available at: https://www.osha.gov/dsg/hospitals/workplace_violence.html. Accessed June 23, 2018.

7. Kim JH, Choi HS, Jung HJ, Lim SG, Lee CM. Workplace violence experienced by emergency department workers and its association with stress and depression assessment. J Korean Soc Emerg Med 2019:30; 257-264.

8. Park S. A patient bit a nurse's finger, which ultimately led to amputation. Available at: http://news.kmib.co.kr/article/view. asp? arcid $=0012065813 \&$ code $=61121211 \& \mathrm{c} p=$ nv. Accessed January 21, 2018.

9. Jung D. Patient kills doctor at a large hospital in Seoul. Available at: http://www.yonhapnewstv.co.kr/MYH20181231015900038/?did=182 
5m. Accessed December 3, 2018.

10. Hwang H. 2019 Novel Coronavirus diagnosed patient spitting at health center staff. Available at: https://www.edaily.co.kr/news/read?newsId=0 4195126625675112\&mediaCodeNo=257. Accessed February 28, 2020.

11. Lanctôt N, Guay S. The aftermath of workplace violence among healthcare workers: a systematic literature review of the consequences. Aggress Violent Behav 2014;19:492-501.

12. Rosenthal LJ, Byerly A, Taylor AD, Martinovich Z. Impact and prevalence of physical and verbal violence toward healthcare workers. Psychosomatics 2018;59:584-590.

13. Bowling NA, Beehr TA. Workplace harassment from the victim's perspective: a theoretical model and meta-analysis. J Appl Psychol 2006; 91:998-1012.

14. Alden LE, Regambal MJ, Laposa JM. The effects of direct versus witnessed threat on emergency department healthcare workers: implications for PTSD Criterion A. J Anxiety Disord 2008;22:1337-1346.

15. Lamothe J, Guay S. Workplace violence and the meaning of work in healthcare workers: a phenomenological study. Work 2017;56:185-197.

16. Mento C, Silvestri MC, Bruno A, Muscatello M, Cedro C, Pandolfo G, et al. Workplace violence against healthcare professionals: a systematic review. Aggress Violent Behav 2020;51:101381.

17. Wilkinson H, Whittington R, Perry L, Eames C. Examining the relationship between burnout and empathy in healthcare professionals: a systematic review. Burnout Res 2017;6:18-29.

18. Hojat M, Louis DZ, Markham FW, Wender R, Rabinowitz C, Gonnella JS. Physicians? empathy and clinical outcomes for diabetic patients. Acad Med 2011;86:359-364.

19. Hojat M, Louis DZ, Maxwell K, Markham FW, Wender RC, Gonnella JS. A brief instrument to measure patients' overall satisfaction with primary care physicians. Fam Med 2011;43:412-417.

20. Derksen F, Bensing J, Lagro-Janssen A. Effectiveness of empathy in general practice: a systematic review. Br J Gen Pract 2013;63:e76-e84.

21. Neumann M, Wirtz M, Bollschweiler E, Mercer SW, Warm M, Wolf J, et al. Determinants and patient-reported long-term outcomes of physician empathy in oncology: a structural equation modelling approach. Patient Educ Couns 2007;69:63-75.

22. Yuguero O, Ramon Marsal J, Esquerda M, Vivanco L, Soler-González J. Association between low empathy and high BMC among primary care physicians and nurses in Lleida, Spain. Eur J Gen Pract 2017;23:4-10.

23. Joint Commission (US). Sentinel event alert 59: physical and verbal violence against health care workers. Available at: https://www.jointcommission.org/en/resources/patient-safety-topics/sentinel-event/sentinel-event-alert-newsletters/sentinel-event-alert-59-physical-andverbal-violence-against-health-care-workers/. Accessed June 23, 2018.

24. Baldry AC. "Stick and stones hurt my bones but his glance and words hurt more": the impact of psychological abuse and physical violence by current and former partners on battered women in Italy. Int J Forensic Ment Health 2003;2:47-57.

25. International Labour Organization, International Council of Nurses, World Health Organization, \& Public Services International. Workplace violence in the health sector country case studies: Research Instruments-Questionnaire. Available at: http://www.who.int/violence injury_prevention/violence/interpersonal/en/WVquestionnaire.pdf. Accessed September 23, 2018.

26. American Psychiatric Association. Diagnostic and statistical manual of mental disorders. 4th ed. Washington, DC: American Psychiatric Association Press; 1994.

27. Chen WC, Hwu HG, Kung SM, Chiu HJ, Wang JD. Prevalence and determinants of workplace violence of healthcare workers in a psychiatric hospital in Taiwan. J Occup Health 2008;50:288-293.

28. Pai HC, Lee S. Risk factors for workplace violence in clinical registered nurses in Taiwan. J Clin Nurs 2011;20:1405-1412.

29. Hojat M, Mangione S, Nasca TJ. The Jefferson Scale of Physician Empathy: development and preliminary psychometric data. Educ Psychol Meas 2001;61:349-365.
30. Bigham BL, Jensen JL, Tavares W, Drennan IR, Saleem Humaira, Dainty $\mathrm{KN}$, et al. Paramedic self- reported exposure to violence in the emergency medical services (EMS) workplace: a mixed-methods cross-sectional survey. Prehosp Emerg Care 2014;18:489-494.

31. Ope-babadele O, Ilesanmi, RE. Pattern of workplace violence and perceived effects on nurses' work productivity in selected hospitals in Ibadan, Oyo State. Int J Nurs Stud 2018:4;105-117.

32. Noda T, Takahashi Y, Murai T. Coping mediates the association between empathy and psychological distress among Japanese workers. Pers Individ Dif 2018;124:178-183.

33. Spector PE, Coulter ML, Stockwell HG, Matz MW. Perceived violence climate: a new construct and its relationship to workplace physical violence and verbal aggression, and their potential consequences. Work Stress 2007;21:117-130.

34. Friborg O, Emaus N, Rosenvinge JH, Bilden U, Olsen JA, Pettersen G. Violence affects physical and mental health differently: the general population based Tromsø study. PLoS One 2015;10:e0136588.

35. Arnetz EJ, Hamblin JL, Russell JJ, Upfal MJ, Luborsky M, Janisse J, et al. Preventing patient-to-worker violence in hospitals: outcome of a randomized controlled intervention. J Occup Environ Med 2017;59:1827.

36. Gerberich SG, Church TR, McGovern PM, Hansen H, Nachreiner N, Geisser M, et al. An epidemiological study of the magnitude and consequences of work related violence: the Minnesota nurses' study. J Occup Environ Med 2004;61:495-503.

37. Hanson G, Perrin N, Moss H, Laharnar N, Glass N. Workplace violence against homecare workers and its relationship with workers health outcomes: a cross-sectional study. BMC Public Health 2015;15:11.

38. Yun JY, Shim G, Jeong B. Verbal abuse related to self-esteem damage and unjust blame harms mental health and social interaction in college population. Sci Rep 2018;9:5655.

39. Jalil R, Huber JW, Sixsmith J, Dickens GL. Mental health nurses' emotions, exposure to patient aggression, attitudes to and use of coercive measures: cross sectional questionnaire survey. Int J Nurs Stud 2017; 75:130-138.

40. Collazzoni A, Capanna C, Bustini M, Marucci C, Prescenzo S, Ragusa $\mathrm{M}$, et al. A comparison of humiliation measurement in a depressive versus non-clinical sample: a possible clinical utility. J Clin Psychol 2015; 71:1218-1224.

41. Hsieh HF, Wang HH, Shen SH, Li YC. Predictors of depressive symptoms among psychiatric nurses who suffered from workplace violence. J Adv Nurs 2018;74:425-432.

42. Kim M. Theoretical Considerations of unintentional verbal violence. Assoc Eng Lang Lit Kor 2015;63:31-51.

43. Neumann M, Edelhäuser F, Tauschel D, Fischer MR, Wirtz M, Woopen C. Empathy decline and its reasons: a systematic review of studies with medical students and residents. Acad Med 2011;86:996-1009.

44. Yoo HJ, Suh EE, Lee SH, Hwang JH, Kwon JH. Experience of violence from the clients and coping methods among intensive care unit nurses working in a hospital in South Korea. Asian Nurs Res 2018;12:77-85.

45. Pai HC, Lee S. Risk factors for workplace violence in clinical registered nurses in Taiwan. J Clin Nurs 2011;20:4505-4512.

46. Gillespie GL, Bresler S, Gates DM, Succop P. Posttraumatic stress symptomatology among emergency department workers following workplace aggression. Workplace Health Saf 2013;61:247-254.

47. Walsht BR, Clarke E. Post-trauma symptoms in health workers following physical and verbal aggression. Work Stress 2003;17:170-181.

48. Ehlers A, Clark DM. A cognitive model of posttraumatic stress disorder. Behav Res Ther 2000;38:319-345.

49. Geiger-Brown J, Muntaner C, McPhaul K, Lipscomb J, Trinkoff A. Abuse and violence during home care work as predictor of worker depression. Home Health Care Serv Q 2007;26:59-77.

50. Chen WC, Wang JD, Lew-Ting CY, Chiu HJ, Lin YP. Workplace violence on workers caring for long-term institutionalized schizophrenic patients in Taiwan. J Occup Health 2007;49:311-316. 
51. Sato K, Wakabayashi T, Kiyoshi-Teo H, Fukahori H. Factors associated with nurses' reporting of patients' aggressive behavior: a cross-sectional survey. Int J Nurs Stud 2013;50:1368-1376.

52. Franz S, Zeh A, Schablon A, Kuhnert S, Nienhaus A. Aggression and violence against health care workers in Germany - a cross sectional retrospective survey. BMC Health Serv Res 2010;10:51.

53. Song SO, Jung CH, Song YD, Park CY, Kwon HS, Cha BS. Background and data configuration process of a nationwide population-based study using the Korean national health insurance system. Diabetes Metab J 2014;38:395-403.

54. Çelik SŞ, Çelik Y, Ağırbaș İ, Uğurluoğlu Ö. Verbal and physical abuse against nurses in Turkey. Int Nurs Rev 2007;54:359-366.

55. Katz LL, Paul MB. When a physician may refuse to treat a patient. Available at: https://physiciansnews.com/2002/02/14/when-a-physicianmay-refuse-to-treat-a-patient . Accessed September 23, 2018.

56. Gillespie GL, Gates DM, Kowalenko T, Bresler S, Succop P. Implementation of a comprehensive intervention to reduce physical assaults and threats in the emergency department. J Emerg Nurs 2014;40:586-591.

57. Ming JL, Huang HM, Hung SP, Chang CI, Hsu YS, Tzeng YM, et al. Using simulation training to promote nurses' effective handling of workplace violence: a quasi-experimental study. Int J Environ Res Public Health 2019;16:3648. 